\title{
Primeiro Workshop Interno dos Serviços de Referência do Centro de Pesquisas Aggeu Magalhães da Fundação Oswaldo Cruz
}

\author{
First Internal Workshop of the Reference Services at \\ Centro de Pesquisas Aggeu Magalhães, Fundação Oswaldo Cruz
}

Recife, PE, 06 de maio de 2008

\begin{abstract}
Abraham Rocha ${ }^{1,5}$, Constança Simões Barbosa ${ }^{1,6}$, Sinval Pinto Brandão Filho ${ }^{2,7}$, Claudia Maria Fontes de Oliveira ${ }^{3,8}$, Alzira Maria Paiva de Almeida ${ }^{4,9}$ e Yara de Miranda Gomes ${ }^{2,10}$
\end{abstract}

0 Centro de Pesquisas Aggeu Magalhães (CPqAM), uma das unidades da Fundação Oswaldo Cruz (FIOCRUZ), Ministério da Saúde (MS), situada em Recife, Pernambuco, desenvolve um trabalho sistemático de pesquisa e ensino em diversos campos da saúde pública, em doenças infecto-contagiosas e no combate a endemias. Ao longo de sua história, o CPqAM, acumulou conhecimento e experiência no campo da pesquisa e ensino, bem como o domínio de procedimentos de alta complexidade, possibilitando dar suporte aos serviços de saúde em diagnósticos diferenciais, tratamento e acompanhamento dos diversos agravos a saúde à população nordestina (disponível no site http://www. cpqam.fiocruz.br).

A Fundação Oswaldo Cruz ao longo dos anos tem sido considerada uma instituição de referência em saúde para várias outras instituições, dentre elas a Secretaria de Vigilância em Saúde, Organização Pan-Americana de Saúde (OPAS), Organização Mundial de Saúde (OMS), Secretarias estaduais e municipais de Saúde ${ }^{10}$.

Os Serviços de Referência (SR) atuam como suporte à vigilância em Saúde, por meio da realização de ensaios laboratoriais, capacitação de recursos humanos, desenvolvimento de tecnologias e prestando assessorias técnicas à Instituições Nacionais e Internacionais. Por outro lado, a relação entre os SR e essas instituições eram caracterizadas por grande fragmentação

\footnotetext{
1. Departamento de Parasitologia Centro de Pesquisas Aggeu Magalhães, Fundação Oswaldo Cruz, Recife, PE. 2. Departamento de Imunologia, Centro de Pesquisas Aggeu Magalhães, Fundação Oswaldo Cruz, Recife, PE. 3. Departamento de Entomologia, Centro de Pesquisas Aggeu Magalhães, Fundação Oswaldo Cruz, Recife, PE. 4. Departamento de Microbiologia, Centro de Pesquisas Aggeu Magalhães, Fundação Oswaldo Cruz, Recife, PE. 5. Serviço de Referência Nacional em Filarioses, Recife, PE. 6. Serviço de Referência em Esquistossomose, Recife, PE. 7. Serviço de Referência em Leishmaniose, Recife, PE. 8. Serviço de Referência em Culicideos Vetores. Recife, PE. 9. Serviço de Referência Nacional em Peste, Recife, PE. 10. Serviço de Referência em Doenças de Chagas, Recife, PE.

Endereço para correspondência: Prof. Abraham Rocha. Dept ${ }^{0}$ de Parasitologia/ CPqAM/FIOCRUZ. Av. Moraes Rego S/N, 50670-420 Recife, PE.

Tel: 55 81 2101-2500/2505

e-mail: rocha@cpqam.fiocruz.br

Recebido para publicação em 28/10/2008

Aceito em 06/03/2009
}

institucional, na medida em que, muitas vezes, esta relação ocorria diretamente entre os laboratórios credenciados ou profissionais específicos.

Esta forma de relação informal não determinava um espaço cristalino no sistema referenciado, podendo provocar certas irracionalidades internas, com duplicação e/ou subutilização das estruturas de serviços. Além disso, esta forma de relacionamento, muitas vezes pode apresentar lacunas nas relações institucionais, tais como: atividades isoladas, a não definição de instrumentos de avaliação de resultados ou mesmo o não cumprimento das metas previamente acordadas ${ }^{1011}$.

No ano de 2001, com o intuito de estabelecer um alinhamento estratégico com as políticas da Fundação Oswaldo Cruz (FIOCRUZ), norteado pelo plano quadrienal 2001-2005 (Diretrizes para a formulação do Plano Quadrienal) ${ }^{11}$, a Vice-Presidência dos Serviços de Referência e Ambiente (VPSRA) e os representantes institucionais da Câmara Técnica de Serviços de Referência (CTSR) (unidades da FIOCRUZ, Rio de Janeiro-RJ, Recife-PE, Salvador-BA, Belo Horizonte-MG e Manaus-AM) juntamente com a Coordenação da Subcâmara Técnica de Laboratórios (SCTL), e os representantes das unidades da instituição FIOCRUZ, definiram um conjunto de requisitos necessários para o reconhecimento interno dos laboratórios de referência. Dessa forma a CTSR e a SCTL elaboraram uma proposta, baseados em normas nacionais e internacionais para a gestão da qualidade em laboratórios de ensaios, que foram avaliadas pelo Conselho Deliberativo da FIOCRUZ. Assim, em 13/09/2002 foi publicada a portaria 430/2002 da Presidência da FIOCRUZ com o propósito de definição dos requisitos que comporiam os critérios para o reconhecimento interno dos Laboratórios de Referência (LR), estabelecendo também o compromisso dos LR em implantar e implementar um Sistema da Qualidade, de acordo com os critérios e cronograma estabelecidos nessa portaria ${ }^{14}$.

A partir dessa definição institucional foram publicadas pelo Ministério da Saúde as portarias de números 409 e 410 em 12 de setembro de 2002. A portaria 409 organiza as sub-redes de 
diagnóstico e vigilância laboratorial no país e a 410 relaciona as instituições que possuem laboratórios pré-selecionados para integrar a rede Nacional de Vigilância Epidemiológica ${ }^{12} 13$. A partir da normalização publicada pelo MS, em 23/07/2003, foi publicada a portaria da Presidência da FIOCRUZ de número 162/2003, regulamentando os SR de Diagnóstico Laboratorial da FIOCRUZ e a execução de atividades para a área de Vigilância Epidemiológica, na condição de Referência Nacional e Regional. Dentre os 27 laboratórios que foram regulamentados por esta portaria seis pertencem ao $\mathrm{CPqAM}^{15}$.

Tendo ainda como meta a definição da reestruturação do Sistema Nacional de Laboratórios de Saúde Pública (SISLAB), bem como ampliar o acesso e a qualidade do sistema laboratorial de referência no País o MS publicou em 23 de setembro de 2004 a portaria de número $2.031^{27}$. Esta portaria definiu que o SISLAB seria formado por um conjunto de redes nacionais de laboratórios organizados em sub-redes, de forma hierarquizada por grau de complexidade, por agravo ou programas, voltados para a realização de atividades de vigilância epidemiológica, vigilância ambiental em saúde, vigilância sanitária e assistência médica.

Tomando como parâmetro esta reestruturação, os Laboratórios foram classificados como Centros Colaboradores, Laboratórios de Referência Nacional, Laboratório de Referência Regional, Laboratório de Referência Estadual, Laboratórios de Referência Municipal, Laboratórios Locais e Laboratórios de Fronteira. Entretanto, para a atuação dos Laboratórios quer seja no âmbito Nacional quer seja no âmbito Regional foram estabelecidos pelo MS critérios para habilitação. Esses critérios foram normalizados pela Portaria de número 70, de dezembro de 2004, republicada em fevereiro de 2005. Dentre os vários itens destacam-se a importância dos Laboratórios em implantar o sistema de qualidade, biossegurança e participar do programa internacional de avaliação externa da qualidade ${ }^{26}$.

Desta forma, uma vez estabelecida a reestruturação do SISLAB, foram referenciados por meio de portarias internas e ministeriais seis Laboratórios de Referência pertencentes ao CPqAM que foram classificados de acordo com a suas áreas de abrangências geográficas e competências. O Serviço de Controle de Culicídeos Vetores, Filariose e Peste são Referências Nacionais, já os Serviços de Doença de Chagas, Esquistossomose Mansônica e Leishmaniose são Referências Regionais ${ }^{1314151726}$.

Com a finalidade de demonstrar a articulação e integração entre a pesquisa e as atividades desses SRs, por meio dos serviços oferecidos, tanto do ponto de vista da capacitação técnica dos profissionais, quanto do domínio de tecnologias, foi realizado o Primeiro Workshop dos Serviços de Referência do CPqAM. 0 evento foi organizado pela Vice-Diretoria de Pesquisa e Serviços de Referência e pela Coordenação Geral dos Serviços de Referência do CPqAM e realizado no dia 06 de maio de 2008 no Auditório Frederico Simões Barbosa.

0 presente relatório apresenta as atividades que são desenvolvidas nesses Serviços e as recomendações apontadas no evento.
TEMA 1: ASPECTOS EPIDEMIOLÓGICOS, CLÍNICOS, LABORATORIAIS E CONTROLE DOS AGRAVOS

\section{ESQUISTOSSOMOSE \\ Prof ${ }^{a}$ Constança Simões Barbosa}

A esquistossomose mansoni é uma infecção parasitária produzida por parasito trematódeo Schistosoma mansoni, cuja sintomatologia clínica depende do estágio de evolução do parasita no hospedeiro. 0 aparecimento de formas graves está relacionado à intensidade da infecção e as principais causas de óbito estão relacionadas às formas clínicas graves. 0 homem é o principal hospedeiro mas roedores e marsupiais são potencialmente infectados. Os hospedeiros intermediários no Brasil são três espécies de caramujos do gênero Biomphalaria: Biomphalaria glabrata, Biomphalaria tenagophila, Biomphalaria straminea. A transmissão da doença se dá quando os ovos do Schistosoma. mansoni são eliminados pelas fezes do hospedeiro infectado (homem). Na água, eclodem, liberando uma larva ciliada denominada miracídio, a qual infecta o caramujo. Após 4 a 6 semanas, abandonam o caramujo, na forma de cercária, ficando livres nas águas naturais. 0 contato humano com águas infectadas pelas cercárias é a maneira pela qual o indivíduo adquire a esquistossomose.

Pernambuco destaca-se por apresentar altas taxas de infecção humana para esquistossomose em áreas rurais ${ }^{4}$ e formas graves da doença ${ }^{2}$. Além disso, novos focos estão sendo detectados no litoral e Região metropolitana do Recife ${ }^{13}$ demonstrando que essa parasitose está se expandindo e fora de controle.

O Laboratório de Esquistossomose do CPqAM vem exercendo suas atividades desde 1985, sediado na Estação de Campo Barca Pellon, município de São Lourenço da Mata, Pernambuco onde foram operacionalizadas diversas atividades de Epidemiologia, Malacologia e Controle da Esquistossomose. A referida Estação de Campo foi também cenário de vários treinamentos em técnicas malacológicas, parasitológicas e epidemiológicas para agentes de saúde da Superintendência de Campanhas de Saúde Pública, Fundação Nacional de Saúde e de municípios de áreas endêmicas sempre tendo em vista aprimorar modelos de intervenção para o controle da esquistossomose. A expressiva produção científica dos pesquisadores e colaboradores deste laboratório, assim como sua ininterrupta interação com os serviços de saúde, propiciou o seu reconhecimento como Serviço Regional de Referência em Esquistossomose Mansônica (SRE) para o MS. Atualmente, o SRE funciona nas modernas instalações do CPqAM/Fiocruz dispondo de uma área física de $600 \mathrm{~m}^{2}$ com instalações laboratoriais e infra-estrutura para atividades de diagnóstico parasitológico, malacológico e operações de campo em esquistossomose. Conta com um corpo técnico efetivo especializado em Malacologia, Parasitologia e Epidemiologia da Esquistossomose. Atua em colaboração com Pesquisadores da Escola Nacional de Saúde Pública (ENSP), Instituto Oswaldo Cruz (IOC), da Universidade Federal de Pernambuco (UFPE) e Universidade Federal Rural de Pernambuco (UFruPE). 
O Serviço de Referência em Esquistossomose apóia e assessora os serviços de saúde na capacitação de recursos humanos para a Epidemiologia e Controle da Esquistossomose oferecendo cursos e treinamentos em: diagnósticos malacológico, parasitológico e epidemiológico. Para manter a infra-estrutura laboratorial e de campo, o laboratório cultiva diversas cepas de Schistosoma mansoni e de Biomphalaria, realiza inquéritos coproscópicos e malacológicos em áreas endêmicas, promove atualizações em epidemiologia da esquistossomose e oficinas de trabalho para elaboração de projetos de controle. A equipe do SRE é formada por uma coordenadora (doutora em Saúde Pública), um Vice-Coordenador (doutor em Saúde Pública), 4 técnicos (3 microscopistas, 1 gerente administrativa) e 2 bolsistas (1 Gerente da Qualidade e 1 Técnico de Operações de Campo).

\section{LEISHMANIOSE}

\section{Prof. Sinval Pinto Brandão Filho}

As leishmanioses encontram-se em expansão em diversas regiões do país, das quais o Nordeste se destaca, com cerca de $80 \%$ dos casos de leishmaniose visceral (LV) e aproximadamente metade dos casos de leishmaniose tegumentar (IT) notificados no paí ${ }^{34}$. Em Pernambuco, ambas as formas da doença encontramse em expansão, onde a LT predominantemente incide na Zona da Mata $^{6}$, com cerca de $60 \%$ dos casos, e a LV no sertão e agreste $^{78}$. Todos os hospitais de referência para leishmaniose encontramse localizados no Recife e há poucas equipes treinadas para a realização do diagnóstico parasitológico e sorológico da doença em toda rede de atenção a saúde do Estado. Neste sentido, o grupo de pesquisa Eco-epidemiologia das leishmanioses do CPqAM, que desenvolve projetos de pesquisa em diversas áreas endêmicas do Estado e fazia espontânea e eventualmente o diagnóstico de maior complexidade para a rede de atenção e vigilância epidemiológica do estado, aceitou em 2001 fazer parte de um grupo interdisciplinar e inter-institucional de unidades de pesquisa da FIOCRUZ, e em 2002 foi formalizado o Serviço de Referência Regional em Leishmaniose (SRL), inserido no Departamento de Imunologia do CPqAM. O Serviço de Referência em Leishmaniose faz parte desde a ocasião, da rede de referência em leishmaniose da FIOCRUZ, constituída por cinco unidades: o Centro de Pesquisas Aggeu Magalhães (CPqAM) em Recife, o Instituto Oswaldo Cruz (IOC) e o Instituto de Pesquisa Clínica Evandro Chagas (IPEC) no Rio de Janeiro, o Centro de Pesquisas René Rachou (CPqRR) em Belo Horizonte e o Centro de Pesquisas Gonçalo Moniz (CPqGM) em Salvador. São objetivos do SRL realizar o diagnóstico parasitológico de maior complexidade das leishmanioses, como o isolamento do parasita e diagnóstico molecular de Leishmania spp em pacientes, diagnóstico parasitológico e molecular em hospedeiros reservatórios domésticos, silvestres e sinantrópicos, diagnóstico da infecção natural e identificação taxonômica de flebotomíneos da fauna regional, treinamento e capacitação de pessoal técnico do nível médio ou superior oriundo de serviços de saúde pública regionais, em laboratório e no campo, nos métodos de diagnóstico parasitológico e entomológico. Com efeito, a expertise do nosso grupo nesta área de atuação atraiu a demanda de órgãos como a Funasa, secretaria estadual de Saúde e secretarias de saúde de alguns municípios da Zona da Mata onde desenvolvíamos atividades de pesquisa, para treinamentos de pessoal técnico e exames de maior complexidade para o diagnóstico etiológico e sorológico, em suporte às ações realizadas pelo Laboratório Central (LACEN) de Pernambuco e pelo programa de controle das leishmanioses da Secretaria de Vigilância em Saúde (SVS), Ministério da Saúde.

A equipe é formada por um coordenador (doutor em parasitologia médica), um vice coordenador (mestre em anatomia patológica), um gerente de qualidade (mestre em medicina veterinária), dois bolsistas de apoio técnico da Facepe e Fiotec (uma bióloga e uma veterinária) e um assistente técnico terceirizado por nossa unidade. 0 Serviço de Referência em Leishmaniose realiza capacitações de equipes técnicas de LACENs dos estados das regiões Norte e Nordeste, vários exames laboratoriais de diagnóstico e algumas consultorias, inclusive na elaboração das novas edições dos manuais de controle da leishmaniose tegumentar e leishmaniose visceral do Ministério da Saúde, respectivamente.

\section{FILARIOSE}

\section{Prof. Abraham Rocha}

A filariose linfática (FL) ou bancroftose, causada pelo helminto Wuchereria bancrofti, é uma infecção parasitária, exclusiva dos seres humanos, transmitida por culicídeo vetor (Culex quinquefasciatus) ${ }^{33}$. A Região Metropolitana do Recife, PE (Recife, Olinda e Jaboatão) são áreas de importante transmissibilidade. 0 município de Maceió, AL tem a infecção sob controle e o município de Belém do Pará, encontra-se em processo de reconhecimento, junto à Organização Mundial da Saúde, da certificação de eliminaçãa $0^{925}$.

No Brasil, as ações de controle e pesquisa sobre 0 agravo da filariose linfática tiveram início na década de 1950. 0 grupo de trabalho (GT) em FL do CPqAM, particularmente do Departamento de Parasitologia, vem desenvolvendo pesquisas, prestação de serviço, assistência, assessorias e treinamento de recursos humanos relacionados ao agravo da FL desde a década de 1980. Diante da luz do conhecimento técnico científico gerado pelo GT em FL ao longo de duas décadas e meia deram suporte ao Ministério da Saúde para credenciar as suas atividades como Serviço de Referência Nacional em Filarioses (SRNF), no ano de 2002. Sendo o único SR em FL no País a abranger atividades de forma multi e interdiciplinar nas áreas clínica, epidemiológica e laboratorial, somando-se as especialidades de urologia e imagem.

O Serviço de Referência Nacional em Filarioses congrega um potencial conhecimento científico para o desenvolvimento de novas ferramentas diagnósticas a serem empregadas na busca da infecção por Wuchereria bancrofti, no âmbito clínico envolvendo toda a área da morbidade, somado a formação de recursos humanos nacionalmente. Recentemente, o SRNF está capacitando os LACENs da Região Norte do Brasil no diagnóstco 
da Mansonella ozzardi, para avaliação dessa parasitose nos diversos estados que compõem esta região, principalmente na região amazônica, como vistas ao desenvolvimento de pesquisa nas diversas áreas do conhecimento.

O Serviço de Referência Nacional em Filarioses é formado por oito profissionais do quadro da FIOCRUZ, sendo eles: três doutores, dois mestres e três profissionais de nível médio, dentre esses um gerente da qualidade. Conta ainda com quatro bolsistas sendo três de nível médio e um de nível superior e um técnico de nível médio cedido pela Fundação Nacional de Saúde. Tem como parceiros vários Municípios da Região Metropolitana de Recife, Universidades, vários Estados da Federação, Organização PanaAmericana da Saúde e Organização Mundial da Saúde.

Com a implementação no Brasil do Programa de Controle e Eliminação da FL (PCEFL), o Serviço de Referência Nacional em Filarioses, vem assessorando as áreas que irão implementar o tratamento em massa com a dietilcarbamazina, no acompanhamento dos casos positivos, bem como o apoio ao plano de morbidade filarial. Além disso, está comprometido com o PCEFL na reavaliação dos focos que desde a década de 60 tem sido considerados extintos, na busca da certificação da eliminação ${ }^{32}$. Em março de 2008 o SRNF foi submetido a auditoria externa de acordo com as exigências da Portaria ministerial de número $70^{26}$, onde foi habilitado, por meio da portaria de número 97 de 23 outubro de $2008^{29}$.

\section{CULICÍDEOS VETORES}

\section{Prof ${ }^{\mathrm{a}}$ Cláudia Maria Fontes de Oliveira}

O Serviço de Referência para Controle de Culicídeos Vetores (SRCCV) do CPqAM faz parte dos 61 laboratórios e departamentos considerados Centros de Referência Nacional ou Internacional por instituições brasileiras e estrangeiras. Fundamentais para as estratégias nacionais de saúde pública, esses centros são capazes de dar respostas imediatas a problemas emergenciais, como epidemias ou novas doenças.

Os culicídeos são insetos da família Culicidae, conhecidos como mosquitos, que recebem atenção especial devido ao seu hábito hematófago, por meio do qual se tornam importantes vetores de doenças.

Nas últimas décadas, a rápida re-emergência da dengue tornou-a a mais disseminada arbovirose de importância na saúde pública em áreas tropicais e subtropicais. Nestas áreas, 50 a 100 milhões de casos de dengue ocorrem a cada ano, principalmente, em ciclos de transmissão urbana onde o vetor é o Aedes (Stegomyia) aegypti ${ }^{21}$.

Culex quinquefasciatus é a espécie de culicídeo mais amplamente distribuída e, provavelmente, a mais abundante no mundo. Além de causar incômodo pela hematofagia, é um competente vetor de agentes patogênicos ao homem, sendo o principal vetor da filariose linfática bancroftiana na Ásia e na África Oriental e o único responsável pela transmissão da Wuchereria bancrofti (forma periódica noturna) nas Américas, onde a endemia localiza-se especialmente em cidades litorâneas, da Costa Rica ao Brasil ${ }^{22}$.
As medidas de controle consideradas viáveis para os culicídeos vetores tem sido aquelas que visam eliminar ou reduzir suas populações ${ }^{20}$. Dessa forma as populações naturais desses culicídeos têm sido expostas continuamente a inseticidas, aos quais podem desenvolver resistência.

A experiência do SRCCV permitiu seu ingresso na Rede Nacional de Monitoramento da Resistência de Aedes aegypti a inseticidas (MoReNa), esta representa um avanço no controle do vetor da dengue no país. E seus resultados têm interação entre a pesquisa acadêmica e a prestação de serviços à saúde que servem como subsidio as decisões do Programa Nacional de Controle da Dengue (PNCD) para indicar alternativas de controle além do manejo de resistência ${ }^{5}$. 0 Serviço de Referência para Controle de Culicídeos Vetores avalia a susceptibilidade de populações naturais de Culex quinquefasciatus ao inseticida biológico Bacillus sphaericus, por solicitação das Secretarias Municipais de Saúde, dessa forma contribui com o plano de controle e eliminação da Filariose no Brasil; testa a atividade tóxica de inseticidas às populações de culicídeos padrão, mantidas em laboratório, sob condições simuladas de campo e laboratório; oferece as Secretarias Municipais de Saúde cursos de treinamento em manejo de culicídeo para a formação de recursos humanos, além de expor, anualmente, suas atividades e serviços na Semana Nacional de Ciências e Tecnologia promovido por àquele Ministério. Essas atividades envolvem 5 servidores do Departamento de Entomologia (3 pesquisadores doutores, 1 tecnologista mestre e 1 técnico de nível médio) dentre esses o tecnologista desempenha a função de gerente da qualidade do SRCCV, 6 bolsistas dos quais 1 é mestre, 4 são graduados e 1 é técnico de nível médio, além de outro técnico, terceirizado, também de nível médio.

As demandas de ensaios realizados no SRCCV advêm de órgãos públicos como Secretarias de Saúde de Estados brasileiros, Universidades e Instituições de Pesquisa.

\section{PESTE}

\section{Prof ${ }^{\mathrm{a}}$ Alzira Maria Paiva de Almeida}

A peste, infecção pela Yersinia pestis, é uma zoonose focal de roedores silvestres e que eventualmente pode infectar o homem ${ }^{1836}$. No Brasil existem duas áreas de focos independentes: o foco do Nordeste, que se estende do Ceará ao norte de Minas Gerais, e o foco da serra dos Órgãos, no Estado do Rio de Janeiro.

O Programa de Controle da Peste (PCP) desenvolve atividades visando ao monitoramento da circulação do patógeno e a proteção das populações humanas e, para aprimorar o sistema de vigilância laboratorial e epidemiológica, a SVS/MS habilitou em 2002 o CPqAM como Referência Nacional em Peste.

O Serviço de Referência em Peste (SRP), componente do Departamento de Microbiologia, produz insumos (antígeno F1, hemácias sensibilizadas com F1, fago antipestoso, antissoros, e conjugado fluorescente anti-F1) que são empregados no diagnóstico e nas pesquisas realizadas no CPqAM, bem como distribuídos para os laboratórios (LACEN) credenciados pela SVS. 
O Serviço de Referência em Peste desenvolve diversos serviços especializados, destacando-se as capacitações de profissionais para as atividades do PCP em campo e laboratório com ênfase na Biossegurança, supervisões das atividades do Programa, pareceres técnicos e elaboração de manuais técnicos. Realiza, também, investigações em campo para isolamento da Yersinia pestis em roedores e pulgas nas áreas focais e desenvolve métodos de diagnóstico sensíveis, rápidos e seguros baseados na $\mathrm{PCR}^{2435}$.

As atividades do SRP envolveram atualmente nove servidores do Departamento (quatro pesquisadores/doutores e cinco técnicos), 17 bolsistas (11 graduados e seis estudantes), três terceirizados de nível médio e três colaboradores de outras instituições (dois de nível superior e um de nível médio). A partir da década de 1980 observou-se um declínio da magnitude da peste, apesar dos focos se manterem ativos, como comprovam as pesquisas realizadas pelo SRP/CPqAM. Tal fato significa que a doença ainda representa uma ameaça real e permanente de acometimento humano nessas regiões, podendo ser estendida para outros lugares, inclusive centros urbanos, e determinar sérias consequiências médicas e socioeconômicas ao País.

A transcendência da zoonose, pois, considerando-se os seus caracteres epidemiológicos, justifica todos os esforços e investimentos realizados para a manutenção de uma vigilância contínua, o que garantirá a proteção das populações humanas.

\section{DOENÇA DE CHAGAS}

\section{Prof ${ }^{\mathrm{a}}$ Yara Gomes}

A doença de Chagas é causada pelo parasita Trypanosoma cruzi que, na natureza, é transmitido ao homem por insetos hematófagos pertencentes à família Reduviidae, da qual os principais gêneros são o Triatoma, Panstrogylus e Rhodnius ${ }^{30}$. Entretanto, o parasita pode ser transmitido por outras vias alternativas: transfusão sanguínea, aleitamento materno, transplante de órgãos, acidentes laboratoriais e vias congênita e oral ${ }^{19}$.

Os métodos parasitológicos diretos ou indiretos (hemocultura e xenodiagnóstico), utilizados na fase aguda da infecção, apesar de apresentarem 100\% de especificidade, apresentam 20-50\% de sensibilidade, são laboriosos necessitando de uma infra-estrutura encontrada em alguns laboratórios de pesquisa. Já na fase crônica da doença, em que não há parasitemia, o diagnóstico é realizado por métodos imunológicos (imunofluorescência indireta (IFI), hemaglutinação (HAI) e enzyme-linked immunosorbent assay (ELISA) que detectam anticorpos antiTrypanosoma cruzi no soro do indivíduo infectado. No entanto, em virtude da existência de antígenos compartilhados com outros parasitas esses testes podem apresentar reações cruzadas o que contribui para a ocorrência de reações falso-positivas com indivíduos portadores de outras doenças, como por exemplo Leishmaniose ${ }^{19}$.

O Serviço de Referência no Diagnóstico da Doença de Chagas (SRDC) foi criado em 2005, nas dependências do CPqAM, com o objetivo de diagnosticar pacientes com resultados duvidosos bem como aqueles com suspeita de contaminação. Nesse sentido, o SRDC tem dado apoio ao Ambulatório de Doença de Chagas do Hospital Universitário Oswaldo Cruz da Universidade de Pernambuco, ao Hospital das Clínicas da Universidade Federal de Pernambuco, a Secretaria de Vigilância em Saúde/PE e ao LACEN/PE que atende pacientes de todo o estado encaminhados pelos hospitais da região nordeste com resultados duvidosos e/ou casos de suspeita de contaminação. Ainda nesse sentido, tem prestado serviço de acompanhamento a recém-nascidos de mães chagásicas, para detectar uma possível transmissão vertical, contribuindo para que o médico neonatologista tenha um apoio laboratorial seguro. Nesse caso o recém-nascido é acompanhado através da realização de testes sorológicos até 6-9 meses de idade, de acordo com o Consenso Brasileiro em doença de Chagas ${ }^{28}$.

Além disso, o SRDC atua na formação de recursos humanos no nível regional, nacional e internacional capacitando profissionais para o diagnóstico parasitológico e sorológico da infecção pelo Trypanosoma cruzi. A assessoria para a CGLAB/SVS/MS, na elaboração de manuais para o diagnóstico da infecção pelo Trypanosoma cruzi é outra atividade desempenhada pelo SRDC. Mantém colaboração com o Laboratório de Referência Nacional para o Diagnóstico da Doença de Chagas na Fundação Nacional Ezequiel Dias (FUNED), em Belo Horizonte, e, com o Laboratório de Doença de Chagas do Hospital das Clínicas da Universidade Federal de Goiás, em Goiânia.

o Serviço de Referência no Diagnóstico da Doença de Chagas encontra-se inserido no Departamento de Imunologia do CPqAM e conta com uma equipe composta por um coordenador (Doutor em Saúde Pública), um vice-coordenador (bolsista, Doutoranda em Saúde Pública), um gerente técnico de qualidade (bolsista, Biólogo) e um técnico (Mestre em Biofísica). Atendendo as normas de biossegurança e com uma gestão de qualidade segura, a equipe está capacitada a realizar o diagnóstico parasitológico e sorológico da infecção pelo Trypanosoma cruzi de acordo com os critérios estabelecidos pelo Ministério da Saúde ${ }^{28}$.

\section{TEMA 2: GESTÃO DA QUALIDADE}

\section{Prof Cláudia Maria Fontes de Oliveira}

Qualidade é uma busca contínua da melhoria dos processos produtivos por meio da manutenção e aprimoramento de um sistema de gestão da qualidade eficaz, que atenda aos requisitos das normas que segue, valorizando a capacitação e o comprometimento dos colaboradores; bem como a contínua adequação de métodos e equipamentos ${ }^{23}$.

Nos SR/CPqAM, a implantação do Sistema da Qualidade tem sido essencial, por tornar possível demonstrar a capacidade de fornecer produtos e/ou serviços conformes com requisitos pré-estabelecidos em norma nacionais ou internacionais. Para tanto, os SR/CPqAM estão organizando seus fluxos produtivos e atividades correlatas para atenderem aos requisitos das normas que os reguem.

A qualidade total está baseada na filosofia dos cinco $\mathbf{S}$, esta corresponde às palavras Seire que significa organização, Seiton é o mesmo que é arrumação, Seiso limpeza, seiketsu padronização 
e Shitsuke disciplina. O desenvolvimento permanente da Filosofia da Qualidade propicia benefícios como padronização de um sistema aplicável à prática de laboratórios e a manutenção de um processo de aprimoramento contínuo $0^{31}$. Portanto, a implantação da qualidade geralmente é um processo demorado e continuado, pois se propõe a estabelecer um controle total de documentos de não-conformidades; de ações corretivas, preventivas e de investimentos; de controle de equipamentos, abrangendo dispositivos de medição, monitoramento e manutenção; além de realizar análise crítica de processos e de procedimentos.

Um gestor da qualidade é um profissional essencial aos Serviços de Referência, pois vai garantir sob total e rigoroso controle o cumprimento dos requisitos necessários à durabilidade da qualidade, evitando que a capacidade de percepção das nãoconformidades seja anulada pela rotina da execução do trabalho. 0 olhar crítico do operador precisa ser aguçado pela busca da qualidade total no seu serviço. Os SR/CPqAM participaram das etapas para a implementação da Qualidade, sendo este esforço parte de um trabalho institucional, onde se tem investido na capacitação de Recursos Humanos; na criação de uma Gerência da Qualidade; oferecendo cursos de Boas Práticas de Laboratório (BPL), e de Formação de auditores internos. Atualmente, o CPqAM conta com um corpo interno de 33 auditores, estes foram formados em cursos ministrados na ENSP e no próprio CPqAM. Os auditores internos do CPqAM têm cumprido rigorosamente o programa de auditorias internas duas vezes ao ano, que tem contribuído para a manutenção da Qualidade nos seus Serviços de Referência.

A qualidade tem sido definida como um processo sem fim, na verdade é um processo contínuo na busca da qualidade total, podendo se tornar estável e capaz de garantir qualidade no que se faz, quando todos os elementos do sistema funcionam plenamente. Portanto, podemos concluir que a qualidade vale o esforço e o custo de implantá-la.

\section{RECOMENDAÇÕES DOS SERVIÇOS DE REFERÊNCIA DO CENTRO DE PESQUISAS AGGEU MAGALHÃES/FIOCRUZ}

1. Promover reuniões internas para os membros dos Departamentos do CPqAM com a finalidade de atualizá-los nos aspectos clínicos, epidemiológicos e diagnósticos sobre os agravos nos quais os SR desenvolvem pesquisa e prestação de serviço.

2. Divulgar os trabalhos desenvolvidos nos SR do CPqAM, no âmbito interno e externo da Instituição, por meio de cartazes, folders e da mídia eletrônica.

3. Os SR do CPqAM deverão apresentar produtividade por meio de atividades específicas de referência (assessorias, publicações, produção de manuais técnicos, laudos dentre outros).

4. Os membros que compõem o CPqAM deverão ser sensibilizados para entender a importância da gestão da qualidade como um item imprescindível na rotina dos SR.

5. A identificação de possíveis parcerias em determinada abordagem técnica, pelos componentes dos SR, deve ser incentivada.

\section{REFERÊNCIAS}

1. Araújo K, Rezendes APC, Souza-Santos R, Silveira Junior JC, Barbosa CS. Análise Espacial dos Focos de Biomphalaria glabrata e de casos humanos de esquistossomose em Porto de Galinhas, Pernambuco. Cadernos de Saúde Pública 23: 409-418, 2007.

2. Araújo K, Silva CR, Barbosa CS, Ferrari TCA . Clinical-epidemiological profile of children with schistosomial myeloradiculopathy attended at the Instituto Materno Infantil de Pernambuco, Brazil. Memórias do Instituto Oswaldo Cruz 101: 149$156,2006$.

3. Barbosa CS, Araújo K, Favre TC, Pieri OS. Spatial distribution of schistosomiasis foci on Itamaracá Island, Pernambuco, Brazil. Memórias do Instituto Oswaldo Cruz 99: 79-83, 2004

4. Barbosa CS, Favre TC, Wanderley TN, Callou AN, Pieri OS. Assessment of schistosomiasis through scholl surveys in the forest zone of Pernambuco, Brazil. Memórias do Instituto Oswaldo Cruz 101: 55-62, 2006.

5. Braga IA, Valle D. Aedes aegypti: Surveillance, Resistance, and Control Alternatives in Brazil. Epidemiologia e Serviços em Saúde 16: 295-302, 2007.

6. Brandão Filho SP, Campbell-Lendrum D, Brito MEF, Shaw JJ, Davies CR. Epidemiological surveys confirm an increasing burden of cutaneous leishmaniasis in North-East Brazil. Transactions of Royal Society of Tropical Medicine and Hygiene 93: 488-494, 1999.

7. Dantas-Torres F, Brandão Filho SP. A leishmaniose visceral é uma doença endêmica em Recife, Pernambuco? Revista da Sociedade Brasileira de Medicina Tropical 38: 361-362, 2005.

8. Dantas-Torres F, Brandão Filho SP. Expansão geográfica da leishmaniose visceral no Estado de Pernambuco, Brasil. Revista da Sociedade Brasileira de Medicina Tropical 39: 352-356, 2006.

9. Freitas H, Vieira JB, Braun R, Medeiros Z, Rocha MME, Aguiar-Santos A, Fraiha H, Rocha A. Workshop para a avaliação da situação epidemiológica da filariose linfática no Município de Belém, Pará, Norte do Brasil. Revista da Sociedade Brasileira de Medicina Tropical 41: 212-216, 2008.

10. Fundação Oswaldo Cruz. Serviços com qualidade: Catálogo dos serviços de referência oferecidos pela Fundação Oswaldo Cruz à sociedade. Ministério da Saúde. Rio de Janeiro, 2000.

11. Fundação Oswaldo Cruz. Diretrizes para a formulação do Plano quadrienal, 2001-2005. Ministério da Saúde. Rio de Janeiro, 2001.

12. Fundação Nacional de Saúde. Portaria $n^{0}$ 409, de 12 de setembro de 2002. Organiza as sub-redes de diagnóstico e vigilância laboratorial no País, integrantes da Rede Nacional de Laboratórios de Vigilância Epidemiológica. Diário Oficial da União, Brasília, DF, 16 setembro Seção 1, p. 38-39, 2002.

13. Fundação Nacional de Saúde. Portaria n ${ }^{\circ} 410$, de 12 de setembro de 2002. Divulga relação de Órgãos/Entidades que possuem laboratórios pré-selecionados para integrar a Rede Nacional de Laboratórios de Vigilância Epidemiológica. Diário Oficial da União, Brasília, DF, 16 setembro, Seção 1, p. 39, 2002.

14. Fundação Oswaldo Cruz. Portaria 430/09-PR, de 13 de setembro de 2002. Rio de Janeiro, 2002.

15. Fundação Oswaldo Cruz. Presidência. Portaria 162/2003-PR, de 23 de julho de 2003. Rio de Janeiro, 2003.

16. Fundação Oswaldo Cruz. Plano quadrienal, 2005-2008: Fundação Oswaldo Cruz, Ministério da Saúde. Rio de Janeiro, 2005.

17. Fundação Oswaldo Cruz. Presidência. Portaria 140/08-PR, de 15 de abril de 2008. Rio de Janeiro, 2008.

18. Gage KL, Kosoy MY. Natural History of Plague: Perspectives from more than a century of research. Annual Review of Entomology 50: 505-528, 2004.

19. Gomes YM, Pereira VRA, Nakazawa M, Rosa DS, Barros MNDS, Ferreira AGP, Silva ED, Ogatta SF, Krieger MA, Goldenberg S. Serodiagnosis of chronic Chagas Infection by using EIE-Recombinant-Chagas-Biomanguinhos kit. Memórias do Instituto Oswaldo Cruz 96:497-501 2001.

20. Gubler DJ. Aedes aegypti and Aedes aegypti-borne disease control in the 1990s: top down or bottom up. Charles Franklin Craig Lecture. The American Journal of Tropical Medicine and Hygiene 40: 571-578, 1989. 
21. Gubler DJ. The global emergence/resurgence of arboviral diseases as public health problems. Archives of medical research 33: 330-342, 2002.

22. Hayes J. Seasonal changes in population structure of Culex quinquefasciatus Say Diptera:Culicidae): study of an isolated population. Journal of Medicine and Entomology 12: 167-178, 1975.

23. John S. Oakland. Gerenciamento da Qualidade Total TQM. Edition Nobel, 2007.

24. Leal NC, Almeida AMP. Diagnosis of plague and identification of virulence markers in Yersinia pestis by multiplex-PCR. Revista do Instituto de Medicina Tropical de São Paulo 41: 339-342, 1999.

25. Lima ARV. Situação epidemiológica da filariose linfática no foco endêmico de Maceió-Alagoas após a implantação do programa de eliminação. Dissertação de Mestrado em Ciências da Saúde da Universidade Federal de Alagoas, Universidade Federal de Alagoas, Maceió, AL, 2007.

26. Ministério da Saúde. Secretaria de Vigilância em Saúde. Portaria $n^{0} 70,23$ de dezembro de 2004. Estabelece os critérios e a sistemática para habilitação de Laboratórios de Referência Nacional e Regional para as Redes Nacionais de Laboratórios de Vigilância Epidemiológica e Ambiental em Saúde. Diário Oficial da União, Brasília, DF, 24 dezembro. Seção 1, p. 57, 2004.

27. Ministério da Saúde. Portaria ${ }^{\circ} 2.031,23$ de setembro de 2004. Dispõe sobre a organização do Sistema Nacional de Laboratórios de Saúde Pública. Diário Oficial da União, Brasília, DF, 24 novembro. Seção 1, p. 60, 2004.

28. Ministério da Saúde. Consenso Brasileiro em Doença de Chagas. Revista da Sociedade Brasileira de Medicina Tropical 38 (supl III):p.7-25, 2005.
29. Ministério da Saúde. Secretaria de Vigilância em Saúde. Portaria nº 97, de 23 de outubro de 2008. Habilitar laboratórios de Referência Nacional e Regional para a Redes Nacionais de Laboratórios de Vigilância Epidemiológica e em Saúde Ambiental. Diário Oficial da União, Brasília, DF, 24 de outubro. Secção 1, p. $51,2008$.

30. Moraes-Souza H, Bordin JO. Strategies for prevention of transfusion-associated Chagas'disease. Transfusion Medicine Reviews 10: 161-170, 1996.

31. Oliveira AS. Qualidade da qualidade: uma perspectiva em saúde do trabalhador Caderno de Saúde Pública 13: 625-634, 1997.

32. Rocha A. Filariose bancroftiana: Avaliação dos Testes de Diagnóstico Disponíveis Frente às Diversas Formas Clínicas da Bancroftose. Tese de Doutorado em Biologia Celular e Molecular. Instituto Oswaldo Cruz, Fundação Oswaldo Cruz, Rio de Janeiro, RJ, 2004

33. Sasa M. Human Filariasis - A Global Survey of Epidemiological and Control. University of Tokyo Press, Japão, 1976

34. Secretaria de Vigilância em Saúde. Ministério da Saúde. Disponível em: http:// www.saude.gov.br/svs. Acesso em set 2008

35. Souza GT, Abath FGC, Leal NC, Farias ACA, Almeida AMP. Development and evaluation of a single tube nested PCR based approach (STNPCR) for the diagnosis of plague. Advances in Experimental Medicine and Biology 603:351-359, 2007.

36. World Health Organization. International meeting on prevention and controlling plague: the old calamity still has a future. 80: 278-284, 2006 